\title{
INTERNAL BRANDING: ANTECEDENTS OF EMPLOYEE ATTITUDES, SATISFACTION, AND ORGANIZATIONAL LOYALTY
}

\author{
Mircea-Andrei SCRIDON ${ }^{*}$ \\ Babeș-Bolyai University, Romania
}

\begin{abstract}
As competition between employers has become more intense in recent years, employee-based differentiation has become one of the strategic solutions for many organizations. The objective of this paper is to test a nomological model between internal branding, attitude, satisfaction, and loyalty. Data were collected through a survey among employees of a leading electronics conglomerate from Romania. While the relationship between attitudes and loyalty is partially mediated by satisfaction, the relationship between internal branding and satisfaction is indirect, with full mediation by attitudes being detected. The results of the study agree with previous studies, which suggested that internal branding influenced certain employee behaviors, such as positive attitudes, satisfaction, or loyalty.
\end{abstract}

JEL classification: M31, M52

Keywords: internal branding, attitudes, satisfaction, loyalty

\section{Introduction}

Building a strong employer brand is critical today, as competition between employers has become more intense in recent years. In this competitive environment, employee-based differentiation has become one of the strategic solutions for many organizations. One of the advantages of using employees as an element of differentiation is that high-performing employees are difficult to replicate by competitors, at least in a short period of time, as they become real assets for their companies (Terglav et al., 2016).

The recognition of employees as a key element of branding led researchers to examine the concept of internal branding. Internal branding is based on the premise that the quality level of the brand is represented through the company's

* Corresponding author. Address: Faculty of Economics and Business Administration, Babeș-Bolyai University, Cluj-Napoca, Romania, andrei.scridon@econ.ubbcluj.ro. ORCID 0000-0001-8243-8695 
employees and this can be achieved by encouraging employees to understand and celebrate the meaning of the brand and acquire the skills and techniques needed to fulfill brand promises (Wang et al., 2019). Many researchers believe that the internal branding message should be aligned with those of the external branding, which targets customers and other stakeholders in order to provide consistent messages (Vatankhah \& Darvishi, 2018).

However, little is known about the mechanism by which internal branding systems influence or lead to the desired results to be reflected in employee behavior. A potential area for understanding the mechanism is the attitude of employees, both towards the workplace and towards the organization. Although this topic has received much attention in practice, the lack of academic research has led some researchers to call for future studies to focus on the role of employee attitudes (Terglav et al., 2016). We address this topic by extending the current research literature with our study. Therefore, the current study examines employees' attitudes as a possible mediator between internal branding and desired outcomes to be reflected in employee behaviors, namely their satisfaction and loyalty. Employee attitudes are considered one of the necessary conditions for high performance in the workplace and the significant contribution to the success of the organization has been demonstrated by Welch (2011).

Building on these ideas, the study continues with literature review, where the relationships between various components of a nomological model are discussed, a methodology section, followed by data analysis and results, and ending in discussion and conclusion section.

\section{Literature review}

Internal branding can be defined as a cultural change within an organization, in which employees become more customer-oriented and more company-oriented. This can be achieved through various internal marketing strategies and tactics, which will ultimately lead to changes in employee behavior. Meanwhile, once the concept of internal branding is understood, each employee must adopt a certain behavior at work that contributes to the success of the company. This behavior must be maintained through various tactics and applied in accordance with the policies and strategies of human resources, internal communication, and corporate marketing (Li et al., 2018; Liu et al., 2017).

De Chernatony (1999) considers that internal branding is an aspect related to the cooperation of the marketing department and the human resources department. It is important to ensure that internal branding activities are in line with the company's marketing strategy and to encourage their employees in implementing this strategy (Terry, 2003). Marketers possess a deep understanding of the accompanying brand for providing a guide for the work, motivations, needs, and desires of individuals (Terry, 2003). Therefore, they can significantly influence the communication of the brand to the internal public and the formation of their perceptions (Terry, 2003). Internal branding also requires the support of key members of the management team, who have the appropriate qualities to create and lead a brand. 
According to the above, we believe that flexible management styles are necessary to ensure a work environment conducive to the development of an internal brand concept within an organization, because the workforce has become incredibly diverse. The currently active workforce comprises four different generations of people who have been trained in different cultural contexts: traditionalists, baby boomers, generation $X$ and millennials. Each generation has different needs and expectations in terms of management style. The key to employee motivation and collaborative management makes every type of employee feel heard. The traditional generation is considered to respect superiors, hierarchy, and to easily obey the rules, while the next generation, baby boomers (born in uncertain times for the future), is known for high adaptability and preference for democratic leadership style. Generation X prefers the type of management based on skills, freedom, and experience. It is much more appreciated by them than loyalty to the company or remuneration. The collaborative and communication-based leadership style in general is specific to the generation of millennials, who are extremely connected because of the years they have developed and flourish when working in teams, share ideas and are empowered to act by positive confirmation for their actions. These being mentioned, we consider that the importance of adapting the leadership style within the teams acquires a high importance, as diversity requires flexibility, and the management style becomes an important influencing factor for a successful internal branding strategy.

One aspect, with important influences on internal branding is quality, which is a complex concept, with major influences in all aspects of internal and external marketing. In order to succeed in building a high-performance work environment, which generates performance both internally - employees and externally - customers, the organization must work on issues related to organizational culture, identifying motivators, management performance, workforce development, efficiency development as well as career development. All the aspects mentioned above are not only elements that are part of the concept of quality, but there are also factors that influence employee satisfaction and involvement. An involved and satisfied employee will convey quality to customers through the work he does. Thus, a company that "sells" quality to customers, will convey to its employees that the brand values are strong, and perceptions related to internal branding will be positively influenced.

Another aspect that can be considered both as an influencing factor and as a component element is communication, both internal and external. This aspect of internal branding refers to the effort made by companies in staff training process to improve the understanding of brand significance, and to ensure that staff has the necessary skills to deliver the promised brand (M'zungu et.al, 2010). Internal branding is considered more effective when employees participate in the creation of the program for internal branding practices, so a two-way communication between employees and management is encouraged in this regard (Punjaisri et al., 2008). Internal branding activities must be supported by the communication strategy that reflects both external and internal messages (Punjaisri et al., 2008). It is necessary for all members of the organization to have easy access to the information needed to increase employees' awareness of the brand (de Chernatony, 2006). The efficiency of communication will depend on the constant strengthening of the brand. In addition, the organization that seeks to maintain brand standards should remunerate and reward employees accordingly (Hoffman \& Mehra, 1999) as well as keep them motivated by various means (M'zungu et.al, 2010). 
In the study conducted by Punjaisri et al. (2008) on employees' perceptions of the internal branding process, it was established that both internal communication programs and training and development programs are considered to be the main internal branding mechanisms influenced by personal and situational variables. Researchers have identified a number of key tools in internal branding: "methods of mass communication" of information to employees in a written form (e.g. newsletters or information boards) and face-to-face communication (e.g. briefing) or team meetings (Punjaisri et al., 2008). Staff preferred face-to-face communication because they were given the opportunity to "clarify things" (Punjaisri et al., 2008). Employees also expressed the idea that the training program, as part of the internal branding program, helped them to improve their perception of the brand (Punjaisri et al., 2008).

The positive attitude of the employees towards the company brand, as well as the positive internal relations between the employees proved to influence a supportive behavior of the brand (Punjaisri et al., 2008).

It is assumed that internal branding must influence employees to achieve their performance at a higher level, by encouraging them to adopt the necessary changes at the cognitive level (attitude) through internal communication actions, and at the level of behavior (workplace performance). through training and remuneration programs. Thus, the concept of internal branding was considered after consulting the literature, a concept with a high degree of abstraction, so in the proposed analytical framework, internal branding will be a latent variable of the second order, with reflections in communication, training - development, and remuneration.

Following the analysis of published studies on the consequences of internal branding actions on employees, we found that attitudes are influenced by them, as well as the need to distinguish between attitudes towards the workplace and attitudes towards the organization in general. At the same time, when internal branding provides employees with clear organizational directions, then the essential tools for providing brand value will have a positive influence on how employees feel at work (employee satisfaction). Thus, we will consider that internal branding will directly influence attitudes and job satisfaction among employees.

Following the aspects stated above, we propose the first set of hypotheses as follows:

$\mathrm{H} 1$ - Internal branding positively influences attitudes towards the workplace. $\mathrm{H} 2$ - Internal branding positively influences attitudes towards the organization. H3 - Internal branding positively influences job satisfaction.

The attitude of the employees is extremely important in maintaining a positive and optimistic work environment in almost any company, this being a particularly good stimulus for innovative behavior of the employees, as well as in retaining the employees in the company. Because positive attitudes are also generated by the emotional involvement in the relationship with the workplace, we believe that attitudes towards those at work and those towards the organization will influence both satisfaction and loyalty. This is the effect of the emotional involvement of the employee, who will try to maintain the same level of satisfaction and loyalty.

Thus, the following set of hypotheses is proposed: 
H4 - Attitudes towards the workplace influences employee satisfaction.

H5 - Attitudes towards the workplace influences employee loyalty.

H6 - Attitudes towards the organization influences employee satisfaction.

$\mathrm{H} 7$ - Attitudes towards the organization influences the employees' loyalty.

The positive results of job satisfaction have been documented by many authors in the literature, so most say that it often influences customer-oriented behavior, increases employee involvement in the organization which results in the development of a relationship of loyalty to employee's company. The existence of relationships between employee satisfaction and their implications on loyalty were identified by Gu \& Siu (2009). At the same time, Lee et al. (2006) show that employee job satisfaction not only improves work performance, but also contributes to employee engagement and loyalty. Also, studies conducted by Fletcher \& Williams (1996), Turkyilmaz et al. (2011), and Wu \& Norman (2006) report a positive relationship between employee satisfaction and loyalty to the organization that lead us to state the following hypothesis:

H8 - Employee satisfaction positively influences loyalty.

The present study considers attitudes (towards the workplace and towards the organization) as a mediator between internal branding and satisfaction. Maslach et al. (2001) demonstrate that attitude is a mediating variable for the relationship between working conditions in the company and the results of actual work, such as satisfaction. Thus, an internal branding program that provides signs of support for employees will initiate a social exchange relationship with them. Over time, employees who have used the benefits of the organization's internal branding program will feel compelled to respect good deeds to ensure an equitable return for their actions.

Employees will demonstrate involvement, as their deeds for reciprocity will be conceptualized in the positive attitudes and contributions to their work beyond the demands of the workplace. Thus, the following hypotheses are proposed:

H9 - Attitudes towards the workplace partially mediates the relationship between internal branding and employee satisfaction.

$\mathrm{H} 10$ - Attitudes towards the organization partially mediates the relationship between internal branding and employee satisfaction.

The proposed model will also test the premises according to which employee satisfaction is a mediator that links the concepts of attitudes, previously presented, to loyalty, so the following final hypotheses are:

H11 - Employee satisfaction partially mediates the relationship between attitudes towards the workplace and loyalty.

H12 - Employee satisfaction partially mediates the relationship between attitudes towards the organization and loyalty. 


\section{Methodology}

In the present study, the target population was people employed in a multinational electronics manufacturer company, Cluj County, Romania branch, which represented approximately 2200 individuals during the data collection period (second semester of 2019). This population was chosen because it was considered appropriate, to provide answers on the issues studied in this paper. Aspects related to the links between internal branding activities and attitude, satisfaction, and loyalty could be easily captured in the environment of the selected company.

Due to the impossibility of participation of the entire targeted population in this study (lack of access), sampling was performed based on the general characteristics of the company's employees. Thus, a non-probabilistic sampling method was used, respectively the rational selection method, resulting in a sample of 263 respondents.

Of the 263 respondents, half were women, the respondents' age varied between 20 and 55, with an average age of approximately 33 years. An overview of the sample structure based on seniority and education level is also provided in table 1.

Table 1: Sample structure based on seniority and education level

\begin{tabular}{lc}
\hline Seniority & $\%$ \\
\hline Less than 1 year & 23,19 \\
2-3 years & 23,59 \\
4-5 years & 28,13 \\
More than 5 years & 25,09 \\
& $\%$ \\
Education level & 36,89 \\
Highschool diploma & 7,98 \\
Bachelor's degree & 50,19 \\
Master's degree & 4,94 \\
PhD
\end{tabular}

Because the relations that are supposed to exist between the elements of the proposed model are dependency relationships, and within the respective model there are multiple relationships between dependent and independent variables, according to Hair et al. (2010), the statistical technique that should be used for their analysis is that of Structural Equation Modeling (SEM).

Considering that all factors are treated in this study as being reflective, covariance-based SEM will be performed using IBM SPSS AMOS 20. Firstly, a Confirmatory Factor Analysis (CFA) resulting in a final measurement model is considered, then measurement scales reliability and validity is assessed, followed up by path analysis for the relationships in the proposed nomological model.

To evaluate the results, the values of several indicators of goodness of the proposed model, the predictive relevance of each dependent variable, as well as the significance of standardized regression coefficients between independent and dependent variables will be examined (Hair et al., 2010; Byrne, 2010). 


\section{Data analysis and results}

\subsection{Measurement model}

As previously mentioned, we begin the data analysis process by performing a confirmatory factorial analysis on the constructs considered within the conceptual model. This determines the construction of a so-called "measurement model", which includes all the variables of measurement of the constructs presumed to exist within the conceptual model. The objectives of a confirmatory factor analysis are (1) to verify the proposed structure of the factors and (2) to identify the need to make significant changes at the level of the proposed structure.

Following the running of the AMOS program, the results obtained for the indicators based on which the quality of this model is evaluated, are presented in table 2.

Table 2: Measurement model - Goodness-of-fit

\begin{tabular}{lccc}
\hline Category & Acronym & $\begin{array}{c}\text { Threshold } \\
\text { value }\end{array}$ & $\begin{array}{c}\text { Observed } \\
\text { Value }\end{array}$ \\
\hline $\begin{array}{l}\text { Absolute goodness of fit } \\
\text { indicators }\end{array}$ & GFI & $\geq 0.9$ & 0.801 \\
& RMSEA & $\leq 0.08$ & 0.078 \\
$\begin{array}{l}\text { Incremental goodness } \\
\text { of fit indicators }\end{array}$ & $\mathrm{AGFI}$ & $\geq 0.8$ & 0.752 \\
$\begin{array}{l}\text { Parsimonious goodness } \\
\text { of fit indicators }\end{array}$ & $\mathrm{CFI}$ & $\geq 0.9$ & 0.925 \\
\hline
\end{tabular}

Source: authors own calculations

From table 2 it can be observed that for most of the indicators the minimum requirement values are exceeded, resulting in an acceptable measurement model.

Based on the final measurement model, the measurement scales reliability and validity - convergent and discriminating -was evaluated. Regarding the reliability in the measurement scales, it is evaluated with the help of the composite reliability, its value for each factor having to exceed the minimum value of 0.7 (Fornell \& Larcker, 1981).

Convergent validity was evaluated by means of average variance extracted, where a value greater than 0.5 for this indicator represents a proof of this type of validity (Fornell \& Larcker, 1981).

Regarding discriminant validity, to confirm it, the square root of the average variance extracted for each individual construct should exceed the bivariate correlation between the respective construct and the other constructs within the measurement model.

The values registered by each construct separately, regarding reliability as well as their validity are presented in table 3 (reliability and convergent validity), respectively in table 4 (discriminant validity). 
As can be seen from the data presented in the two tables, each construct fulfills the minimum conditions for reliability, convergent validity, and discriminant validity.

Table 3:- Construct reliability and convergent validity

\begin{tabular}{lcc}
\hline & Composite Reliability & Average \\
\hline Loyalty & 0,870 & 0,685 \\
Satisfaction & 0,795 & 0,563 \\
Workplace attitudes & 0,862 & 0,623 \\
Organizational attitudes & 0,891 & 0,675 \\
Internal branding & 0,886 & 0,955 \\
\hline
\end{tabular}

Source: authors own calculations

Table 4: Construct discriminant validity

\begin{tabular}{|c|c|c|c|c|c|}
\hline & Loyalty & Satisfaction & $\begin{array}{l}\text { Workplace } \\
\text { attitudes }\end{array}$ & $\begin{array}{c}\text { Organizational } \\
\text { attitudes }\end{array}$ & $\begin{array}{c}\text { Internal } \\
\text { branding }\end{array}$ \\
\hline Loyalty & 0,830 & & & & \\
\hline Satisfaction & 0,722 & 0,751 & & & \\
\hline $\begin{array}{l}\text { Workplace } \\
\text { attitudes }\end{array}$ & 0,763 & 0,695 & 0,798 & & \\
\hline $\begin{array}{l}\text { Organizational } \\
\text { attitudes }\end{array}$ & 0,805 & 0,621 & 0,788 & 0,821 & \\
\hline Internal branding & 0,824 & 0,711 & 0,752 & 0,809 & 0,980 \\
\hline
\end{tabular}

Source: authors own calculations

\subsection{Structural model}

Having as a starting point, the proposed research hypotheses, a structural model for testing the causal relationships assumed to exist between these constructs will be built based on the constructs in the measurement model.

It is worth mentioning that before the structural model was built, using the AMOS program, the values for each construct in the model were calculated using 
imputation. The reason for this approach was to "simplify" the construction of the structural model, as there is no difference in terms of the results obtained between using these newly calculated values or the old values within the measurement model.

Based on the data in table 5, the causal relations supposed to exist between the factors within the proposed structural model will be validated or not.

The mediation hypothesis where tested by comparing direct effects with indirect effects and forming thus a conclusion. The results are presented in table 6.

Table 5: Standardized regression weights

\begin{tabular}{lllll}
\hline Endogenous variable & & Exogeneous variable & Estimate & p-value \\
\hline Workplace attitudes & $<---$ & Internal branding & 0,362 & ${ }^{*}$ \\
Organizational attitudes & $<---$ & Internal branding & 0,566 & $* *$ \\
Satisfaction & $<---$ & Internal branding & 0,002 & n.s. \\
Satisfaction & $<---$ & Workplace attitudes & 0,256 & $* * *$ \\
Satisfaction & $<---$ & Organizational attitudes & 0,321 & $* *$ \\
Loyalty & $<---$ & Workplace attitudes & 0,156 & $* * *$ \\
Loyalty & $<---$ & Organizational attitudes & 0,201 & $* * *$ \\
Loyalty & $<---$ & Satisfaction & 0,565 & $* *$ \\
\hline
\end{tabular}

$p$-value - ${ }^{*} p<0.05 ;{ }^{* *} p<0.01 ;{ }^{* * *} p<0.001 ;$ n.s.- non-significant.

Source: authors own calculations

Table 6: Direct and indirect effects

\begin{tabular}{cccc}
\hline Hypothesis & Direct effect & Indirect effect & Conclusion \\
\hline H9 & 0,002 n.s. & $0,352^{* * *}$ & Full mediation \\
H10 & 0,002 n.s. & $0,421^{* * *}$ & Full mediation \\
H11 & $0,156^{* * *}$ & $0,224^{* * *}$ & Partial mediation \\
H12 & $0,201^{* * *}$ & $0,256^{* * *}$ & Partial mediation \\
\hline
\end{tabular}

$p$-value - ${ }^{*} p<0.05 ;{ }^{* *} p<0.01 ;{ }^{* * *} p<0.001 ;$ n.s.- non-significant.

Source: authors own calculations

In the following section the results are discussed by comparing them with results from several previous studies conducted on internal branding actions and satisfaction or loyalty. 


\section{Discussion}

The study provides empirical evidence that the internal branding effort, which incorporates training, communication, and remuneration, has a positive effect on employee attitudes. One of the critical success factors for today's organizations is the performance of employees at work, achieved through the positive attitude towards the organization they belong to. The current study shows that in order to encourage employees to have a positive attitude towards the organization in general, it is essential that companies first focus on internal branding through an internal system of communication, training, and remuneration.

This finding is consistent with the theory of social identity proposed by Tajifel \& Turner (1985), which implies that employees who receive support from the organization (through internal branding actions in this case), will show positive attitudes both to the workplace, as well as to the organization to which they belong to, by involvement in the workplace and involvement in the organization, insofar as they identify with the organizational brand.

Although Kahn (1990) compares the term employee involvement with the feeling of their moral obligation to become more involved in their role and to be satisfied with their job in exchange for the resources they receive from the organization, the results of the study could not support this hypothesis. Thus, although the internal branding actions do not influence the level of employee satisfaction, the positive attitudes towards the organization manage to influence the degree of employee satisfaction.

Given that internal branding actions do not influence employee satisfaction, and attitudes positively influence employee satisfaction, we tested a hypothesis according to which attitudes partially mediates the relationship between internal branding actions and satisfaction. This hypothesis was also tested and confirmed by Lee \& Kim (2015), and by Maslach et al. (2001). In line with expectations, the hypothesis was confirmed also, in the present study.

Because studies conducted by Gu \& Siu (2009), Lee et al. (2006), and Fletcher \& Williams (1996) demonstrated the existence of links between attitude, satisfaction, and loyalty, the proposed nomological model links the concepts previously mentioned, through both direct and indirect relationships. Thus, we found that although the attitude of employees positively influences loyalty, it is also mediated trough satisfaction.

Although not all direct links between the concepts of attitude, satisfaction, and loyalty were confirmed, after testing the existence of mediating relationships between the concept of attitude and loyalty, it was found that satisfaction mediates the relationship between attitude and loyalty, which is why we support the results of the previous studies.

Following the above, we discovered that the internal branding actions carried out by the company mentioned in the methodology section, namely actions related to internal communication, training programs, and remuneration, positively influence the attitude of the company's employees. At the same time, the attitude of the employees participating in the study, positively influences both their satisfaction and loyalty, which means that attitude is an important factor, which encourages employees to develop behaviors that positively contribute to employee satisfaction and loyalty. 


\section{Conclusion}

Considering the results, this paper contributes to the general knowledge of the concept of internal branding. The incorporation of internal branding concepts with those related to the behaviors developed by employees of large companies, namely attitudes, satisfaction, and loyalty, could be considered a plus, as most studies analyze at most two concepts simultaneously, without considering possible relationships, existing between several concepts, as we tried in the present study.

The importance and influence of internal branding actions on the attitude of employees towards the organization they belong to, is emphasized in this study. Also, it contributes to strengthen the theory of social exchanges, which argues that if an individual receives benefits (in this case, remuneration, training, and adapted communication) from another party or person, will have to offer in return other benefits (in this case, positive attitude, which determines satisfaction and loyalty).

\section{References}

Byrne, B. M. (2010). Structural equation modeling with AMOS: Basic concepts, applications, and programming. 2nd Edition. Routledge Taylor \& Francis.

de Chernatony, L. (1999). Brand management through narrowing the gap between brand identity and brand factors driving successful financial services brands. European Journal of Marketing, 15(1/3), 157-179.

Fletcher C., Williams, R. (1996). Performance management, job satisfaction and organizational commitment. British Journal of Management, 7(2), 169-179.

Fornell, C., \& Larcker, D.F. (1981). Evaluating Structural Equation Models with Unobservable Variables and Measurement Error. Journal of Marketing Research, 18(1), 39-50.

Gu, Z., \& Siu, R. C. (2009). Divers of job satisfaction as related to work performance in Macao casino hotels: An investigation based on employee survey. International Journal of Contemporary Hospitality Management, 21(5), 561-578.

Hair, J., Black, W., Babin, B., and Anderson, R. (2010). Multivariate data analysis (7th ed.). Prentice-Hall, Inc. Upper Saddle River, NJ, USA.

Hoffman, J., \& Mehra, S. (1999). Operationalizing productivity improvement programs through total quality management. International Journal of Quality and Reliability Management, 16(1), 72-73.

Kahn, W.A. (1990). Psychological conditions of personal engagement and disengagement at work. Academy of Management Journal, 33(4), 692-724.

Lee Y. K., Nam J. H., Park D. H., Lee K. A. (2006). What factors influence customeroriented prosocial behavior of customer-contact employees? Journal of Services Marketing, 20(4), 251-264.

Lee Y.K, Kim S., Kim S.Y. (2015) The Impact of Internal Branding on Employee Engagement and Outcome Variables in the Hotel Industry. Asia Pacific Journal of Tourism Research. 19(12), 1359-1380.

Li C., Guo S., Cao L., Li J., (2018). Digital enablement and its role in internal branding: A case study of HUANYI travel agency. Industrial Marketing Management, 72, 152160. 
Liu G., Ko W.W., Chapleao C. (2017). Managing employee attention and internal branding. Journal of Business Research, 79, 1-11.

M'zungu, S. D., Merrilees, B., \& Mille, D. (2010). Brand management to protect brand equity: A conceptual model. Brand Management, 17(8), 605-617.

Maslach C., Schaufelli W. B., Leiter M. P. (2001). Job burnout. Annual Review of Psychology, 52(1), 397-422.

Punjaisri, K., Wilson, A., \& Evanschitzky, H. (2008). Exploring the influences of internal branding on employees' brand promise delivery: Implications for strengthening customer-brand relationships. Journal of Relationship Marketing, Vol. 7, No. 4, pp. 407-423.

Tajfel, H., Turner, J.C. (1985). The Social Identity Theory of Intergroup Behavior. In:

Worchel, S. and Austin, W.G., Eds., Psychology of Intergroup Relations, 2nd Edition, Nelson Hall, Chicago, pp. 7-24.

Terglav K., Ruzzier M.K., Kaše R. (2016). Internal branding process: Exploring the role of mediators in top management's leadership-commitment relationship. International Journal of Hospitality Management, 54, 1-11.

Terry, N. (2003). Marketers merit a greater role in internal activity. Marketing, pp. 18.

Turkyilmaz A., Akman G., Ozkan C., Pastuszak Z. (2011). Empirical study of public sector employee loyalty and satisfaction. Industrial Management \& Data Systems, 111(5), 675-696.

Vatankhah S., Darvishi M. (2018). An empirical investigation of antecedent and consequences of internal brand equity: Evidence from the airline industry. Journal of Air Transport Management, 69, 49-58

Wang Y.C., Yang J., Yang C.E. (2019). Hotel internal branding: A participatory action study with a case hotel. Journal of Hospitality and Tourism Management, 40, 3139.

Welch M. (2011). Appropriateness and acceptability: employee perspectives of internal communication. Public Relations Review, 38, 246-254.

Wu L., Norman I. J. (2006). An investigation of job satisfaction, organizational commitment and role conflict and ambiguity in a sample of Chinese undergraduate nursing students. Nurse Education Today, 26(4), 304-314. 